\title{
Review of $\boldsymbol{A}$ Dictionary of Global Huayu ${ }^{1}$
}

\author{
Rui Li \\ College of Chinese Language and Culture, Jinan University, China \\ E-mail: ruirui-880721@163.com
}

Doi:10.7575/aiac.alls.v.7n.3p.282

Received: 03/02/2016

URL: http://dx.doi.org/10.7575/aiac.alls.v.7n.3p.282

Accepted: 15/04/2016

This paper has been sponsored by Jinan University.

\begin{abstract}
Abstract: As the first Huayu dictionary published by the Commercial Press, A Dictionary of Global Huayu (Chinese Language) did a pioneer work in many aspects. It did expand the influence of Chinese and provided Chinese speaker abroad a valuable reference book for study and communication. Nevertheless, there are still some demerits. First of all, the amount of entries is less enough and balanced; the definitions are less accurate; the Chinese context is not adequately taken into consideration; and compared with written form, the spoken form is not paid enough attention.
\end{abstract}

Keywords: A Dictionary of Global Huayu, Huayu dictionary, review

\section{Introduction}

A Dictionary of Global Huayu (Chinese Language) is the first Huayu dictionary in the world which records varieties of Chinese language in different countries and regions in China. Nowadays Chinese is not only the China's language, but also a language used all over the world. Differences between Huayu and Chinese are no longer sheer divergences of linguistic terminology. (Guo 2006) According to Guo (2004), Huayu is the common language of ethnic Chinese by the standard of Putonghua (Mandarin). Huayu is distributed in mainland, Taiwan, Hong Kong, Macao, Singapore, Malaysia, Thailand, Indonesia, Vietnam, Brunei, the Philippines, Cambodia, Laos, Burma, etc. Huayu not only includes the varieties of Putonghua, but also the varieties of Chinese dialects such as Cantonese, Min dialect.

A Dictionary of Global Huayu (Chinese Language) has been published both in China and Singapore. The honorary consultants are respectively Lee Kuan Yew, the former Prime Minister of Singapore, and Li Ruihuan of the former member of the Standing Committee of the Political Bureau of the CPC Central Committee. There are 12 universities and institutes participating in compiling and over 30 compilers coming from China, Singapore and Malaysia, etc.

A Dictionary of Global Huayu (DGH in brief) follows the descriptivism and mainly records the featured and distinctive words and senses. (Preface) The aims of compiling DGH are on the one hand, promoting communication, enhancing mutual understanding (Yu 2010), and strengthening the unity between ethnic Chinese; on the other hand, speeding up the pace of convergence of words, and facilitating the Chinese language learners. (Preface)

\section{Outside matter}

DGH that published by the Commercial Press is covered by yellow hardcover (Singapore version by blue softcover). DGH contains 36 pages of front matter, including the title page, copyright notice, preface, guide for dictionary use, table of contents, and two methods of index based on phonetics and strokes (22 pages). It also contains 12 pages of back matter, appendix, including the Chinese Phonetic Alphabet in the Pinyin system, the comparison of distinctions of graphic in same Chinese characters, the comparison of distinctions on names of same countries and capitals in the Huayu circle.

\section{Word collection}

DGH has two wordlists, of which the main one includes 10110 words (counted by the author). Another wordlist covers the 162 words begun with a letter or number, which are divided into seven types. They are abbreviations such as DINK (the abbreviation of dual income no kids), letter words such as QQ (a corresponding software in the Internet), the combinations of letters and characters such as band 仔 (the member of the band), the combinations of letters and numbers such as BIG5 (a standard of Chinese character encoding), the combinations of numbers and characters such as 916 金 (22 karat gold) and the combinations of numbers and letters such as 3T (a term of horse racing). The including of letter words in Chinese dictionaries is recently a widely controversial issue in China, which we will not mention the details.

According to the guide, the words included in DGH have been used by ethnic Chinese communities all over the world since 1980s. The Chinese communities here refer to communities in China (mainland, Hong Kong, Macao, Taiwan) and in Southeast Asia (Singapore, Malaysia, Thailand, Indonesia), and in other countries (Japan, Australia, American, 
Canada, etc.). Most included words are specialties of certain regions and countries, but a few of them are common words shared by all ethnic Chinese such as 家庭影院 (home theater).

Generally speaking, DGH keeps a good balance in words collection among countries and regions, according to my rough statistics. Among the over 10000 included words, more than 1400 words are generic words used by all Chinese communities around the world; over 5000 words are used in the mainland (all including the generic words below); and more than 4200 words are all used in Hong Kong (about 4270 words) and Macao (about 4265 words); and more than 3350 words in Taiwan. There are also more than 1800 words all used in Singapore, Malaysia and Thailand. The dictionary even contains 45 words used in Chinese communities in Japan and 11 words in Canada.

\section{Article}

Compared with A Dictionary of Contemporary Chinese (the most authoritative monolingual Chinese dictionary in China, DCC in brief), which applies characters as headwords; DGH uses words (containing one to five characters, even letters and numbers) as headwords. The headwords have been presented in both simplified Chinese characters (bolded) and traditional Chinese characters with a slash between them, such as 白鸽笼/白鴿籠. The mainland mainly uses the simplified Chinese characters, Singapore and Malaysia as well; while Kong Hong, Macao and Taiwan uses the traditional Chinese characters.

The dictionary offers phonetic information by Pinyin (Chinese Phonetic Alphabet), based on the pronunciation of Putonghua. As same as DCC, the dictionary only supplies the original tones of the characters without considering the tone sandhi, and the retroflex suffixation will be presented by adding " $\mathrm{r}$ " behind. But, for certain characters, which could be spoken in retroflex suffixation alternatively, the " $r$ " will not be added in the dictionary; as a result of that retroflex suffixation is only common in Mandarin. The dictionary offers parts of speech in abbreviations. For example, “形” is short for “形容词” (adjective).

The definitions given in the dictionary are clear and simple in standard Mandarin. The definitions could be equivalents in Mandarin such as 乃, 先生 (Nai, sir), and explanations in words, phrases or sentences. As for terms, encyclopedic information is offered in details. For example, 【派位】指电脑派位. 教育部门用电子计算机随机抽取号码的方式, 将小学升初中的学生分配到本学区的某一学校就读. (【Aided Allocation】 refers to Computer Aided Allocation. The Department of Education uses the computer to randomly allocate in schooling, i.e. the entering to a certain junior middle school from primary school in certain areas). To save the space, the dictionary uses internal references instead of definitions to the words whose full-equivalents have been already included with definitions. For example, 【纳骨塔/ 納骨塔】义同“灵骨塔”(见 539 页). (【naguta】 has the same meaning of “lingguta”, see page 539)

The dictionary provides etymological information to most of articles, which are not used in mainland. The etymological information given behind definitions is related to the whole headword such as【乃】泰语音译 (【Nai】 is the transliteration from Thai), or part of the headword, such as【牛记/牛記】记: 粤方言后缀 (【niuji】, ji: a suffix in Cantonese). Some of the articles label the style, such as【牛气/牛氣】多用于ロ语 (【niuqi】 Being inclined to colloquial language). The dictionary also introduces metaphor meanings of the words, for example, 牛肉干/牛肉乾, 喻 指交通违章罚款通知书。含诙谐意。因港澳常吃的牛肉干是片状棕红色的那种, 而交警开的罚单是棕红色长方 形的, 远看酷似牛肉干, 故称。(beef jerky, refers to the traffic violation penalty notice in metaphor, with a sense of humor. The beef jerky in Hong Kong and Macao is flakes in brownish red, which is similar to rectangle penalty notice delivered by the police.)

The dictionary also shares large space for illustrative examples for different senses of words, including phrasal and sentential examples. The phrasal examples are typical uses of the headwords to some extent, while the sentential examples create the complete context. In fact, almost half of sentential examples are long sentences, presenting better context for the individual words. For example, 仪队/儀隊 (honor guard) has two senses, each of which has one illustrative example as follows.

【仪队/儀隊】...[例] 日本首相在机场第二贵宾大厦前检阅了由新加坡武装部队突击队和宪兵单位人员 组成的 / 在校庆仪式后, 表演活动随即展开, 有 、啦啦队的演出, 成员个个服装亮丽, 吸引众人的 目光。(【honor guard】...[example]Prime Minister of Japan inspected the guard of honor composed of the commandos of the Singapore Armed forces and gendarmerie units in front of the second airport VIP mansion. I After the school anniversary ceremony, the performance starts immediately including the performance of the guard of honor and cheerleaders with beautiful costumes, caught everyone's eyes.)

I have counted the illustrative examples of the articles that phonetically begin with the letter " $\mathrm{A}$ " in DGH, in comparison with the monolingual DCC. DGH includes 120 articles that phonetically start with the letter "A". The 120 articles in DGH have 133 senses in all; while the corresponding articles in DCC ( $5^{\text {th }}$ edition) have 346 senses and in DCC ( $6^{\text {th }}$ edition) 356 senses. (see below)

\begin{tabular}{|c|c|c|c|}
\hline & DGH & DCC $\left(5^{\text {th }}\right.$ edition $)$ & DCC $\left(6^{\text {th }}\right.$ edition $)$ \\
\hline Senses & 133 & 346 & 356 \\
\hline Illustrative examples & 226 & 554 & 575 \\
\hline $\begin{array}{l}\text { Average number of illustrative } \\
\text { examples for each sense }\end{array}$ & 1.67 & 1.60 & 1.62 \\
\hline
\end{tabular}


From letter A section, 1.67 illustrative examples have been given for each sense in average in DGH, keeping a very good balance with $\mathrm{CDD}\left(5^{\text {th }}\right.$ and $6^{\text {th }}$ edition $)$.

As we mentioned, the definitions are given in standard and simplified Mandarin. However, the illustrative examples are given in featured and local Huayu to create more authentic context for the words. For example，【开台/開檯】港澳酒 楼的晚宴往往未食饭就先～打麻将. (【kaitai】 to set the table for meals or playing Mahjong. During the banquets in the restaurants of Hong Kong and Macao, people usually set the tables for playing Mahjong before eating.) In this sentence, “未食饭” is typically used in Hong Kong, Macao and Taiwan, rather than in mainland.

The dictionary labels the region of usage after examples. The labeled regions include mainland, Hong Kong, Macao, Taiwan, Singapore, Malaysia, Thailand, Indonesia, Vietnam, Brunei, Japan, Canada, America, the Philippines, Cambodia, Laos, Burma, and so on. As to the universal words, they will be labeled as "all regions". Some words could be used in different regions in different meanings, which will also labeled in details. Most of the labels are used in abbreviations unless the words are only used in one region. For example, “印尼” is short for “印度尼西亚” (Indonesia); “新” is short for “新加坡” (Singapore).

The dictionary provides the variant forms of the headword labeled by regions of usage. Lastly, there are information boxes containing background knowledge, detailed introductions, quotations, etymological information, etc. for the words, esp. for terms and culture words.

\section{Criticisms}

As the first Huayu dictionary, DGH has done a good job in many aspects. However, there is still space for improvement. First of all, the words collection is less comprehensive on one hand; on the other hand, some included words are still in question. As I have counted, the dictionary covers 10110 articles, of which 1400 words are generic words, and over 5000 are used in mainland. So it is inevitable that the collection is less comprehensive, except for the words used in China. For example, 长屋/長屋 (Changwu) is a distinctive Huayu words in Malaysia which is neglected to include. Changwu (long house) is a kind of traditional house in Malaysia, which is built along the river, about 10 to 100 meters long. Sin Chew Daily has reported a piece of news about Changwu (see http://news.sinchew.com.my/node/368990) in 3 June, 2014. “身家” (shenjia) in Malaysia refers to the assets who possesses. Meanwhile, “身家” in Mandarin used to be family background or somebody with his family, but contemporarily means the assets who possesses as well. So “身家” as a featured and distinctive word should have been included, labeled the original and contemporary meanings with use areas (but not, unfortunately).

As I counted, 1800 words used in Singapore have been included (of which 1400 words are used in common Huayu circle), which means only less than 400 words are included as the distinctive words used in Singapore. But as Zhou said, there are thousands of words in Singapore that are different from Mandarin. As a descriptive global Huayu dictionary, it is necessary to collect the distinctive words comprehensively. Meanwhile, over 5000 Mandarin words have been included, occupying half of the dictionary space. But some of them are not necessary to include, such as rarely used words and indistinctive words. For example, 城徽 (chenghui, the symbol of city) in DGH is labeled as “used in mainland", but it is a rare word in Chinese. Chenghui (城徽) hasn't been included by DCC. Besides, from the large Chinese corpus “语料库在线” (http://www.cncorpus.org/index.aspx), which contains nearly twenty million tokens (i.e. characters, letters, etc.), the word “城徽” is also not collected at all. Another example for unnecessary collection is 创意 /創意 (chuangyi, originality). "Chuangyi” in DGH is labeled as "using in all regions", so it is commonly used in Huayu circle. It is indeed a very common and indistinctive word in Mandarin, which is not a featured word fit for words collection in DGH. In addition, the collection should also pay attention to the balance of counterpart words. For example, the dictionary has included “老妈子/老媽子” (old mother) but neglected the counterpart “老爷子/老爺子” (old father).

Second, the dictionary provides Pinyin as phonetic information, only based on the pronunciations of Putonghua, rather than the authentic pronunciations. From this aspect, the dictionary could only help users in written language, rather than oral communication. Thus, from my point of view, two pronunciations should be both provided.

Third, the dictionary neglects certain senses of words, such as 牛肉干/牛肉乾(beef jerky).

【牛肉干/牛肉乾】niúròugān [名] 喻指交通违章罚款通知书。含诙谐意。因港澳常吃的牛肉干是片状 棕红色的那种, 而交警开的罚单是棕红色长方形的, 远看酷似牛肉干, 故称。[例] ... 使用地区 港澳、 台湾 (【beef jerky】 niúròugān, [n.] refers to the traffic violation penalty notice in metaphor, with a sense of humor. The beef jerky in Hong Kong and Macao is flakes in brownish red, which is similar to rectangle penalty notice delivered by the police. [example] ... Use areas: Hong Kong, Macao, Taiwan)

The beef jerky used in mainland is a popular kind of snack, shaped in flakes in brownish red made by beef. But the dictionary neglected to include the commonest sense and use of regions. The same problems happen to 沙龙/沙龍 (shalong, a kind of skirt). The dictionary has missed the sense of 沙龙/沙龍(as salon), a very common sense used in mainland.

The definitions given by the dictionary should be simple, and most importantly, accurate. A few of definitions are ambiguous (examples will be added, which I have found before). Besides, there are also a few inaccurate definitions. For example, 峇荅 (baba, ethnic Chinese) in DGH is explained as follows.

【峇峇】在东南亚当地出生的男性华人。他们已经不大会说华语, 以讲英语或马来语为主, 但仍保留 华人的习俗。马来语音译。[例]除了少数用方言的，大部分 对中华文化、中国文字已经不太了解。 
使用地区 新马泰印尼文莱 (【baba】 The ethnic male Chinese born in Southeast Asia. They could hardly speak Huayu, instead, they mainly speak English or Malay. But they have preserved the custom and tradition of Chinese. It is the transliteration from Malay. [example]... Use areas: Singapore, Malaysia, Thailand, Brunei, Indonesia)

In fact, according to Huang (2003:10-11), "baba" has two senses, broad and narrow senses. In the narrow sense, "baba" refers to the male ethnic Chinese born in Southeast Asia; and it has the counterpart called Nyonya (娘惹), the female. But in the broad sense, "baba" contains male and female both, referring to all ethnic Chinese born in Southeast Asia. Besides, when "baba" is used in compounds, it usually refers to the broad sense, such as 荅荅华人 (baba ethnic Chinese), 荅荅人(baba Chinese), 荅荅文化(baba culture), 荅荅社会(baba society), 荅荅语(baba Malay). So the two senses of "baba" should not be neglected and the use of "baba" in compounds should be taken into consideration in illustrative examples.

Chinese language is strongly dependent on context, so the illustrative examples, which provide context to individual words, are necessary and important. The dictionary has done a good work in illustrative examples. It offers both phrasal and (long) sentential examples in featured and local Huayu, rather than in Mandarin, which provides more authentic context for individual words. But not all the illustrative examples are in high quality. For example, 烂尾房 refers to the unfinished building or house due to lack of money, etc. In DGH, the example is given as follows.

【烂尾房】[例] 日本 致华人受害，侨民购房需慎重。使用地区 大陆（【unfinished building】 [example]

The Japanese hurts the ethnic Chinese, so Chinese people should buy houses in discretion. Use of area: mainland)

“房”(house) is commonly used in all Huayu regions, and “烂尾房” is only used in mainland. But literally speaking, “烂 尾房” means “worn-out tailed house”. In the sentence, “致...受害”(make ... get hurt) mainly means getting serious hurt, or getting killed, not only mentally, but physically. In DCC, “受害”(get hurt) is explained as “遭到损害或杀害 "(get hurt or killed). And because of some historical reasons, to mention the hurt that Japanese caused, some very bad behaviors might come to mind for Asian. So this sentence delivers vague context, and dictionary users may misunderstand it as that "the worn-out Japanese building collapses and hurts the ethnic Chinese, so Chinese people should buy houses in discretion". Therefore, the illustrative examples are very important for making context, but vague context should be avoided.

The illustrative examples should provide complete context for individual words; otherwise, they are useless. For example, “美得冒泡” means very beautiful but it is usually used in satire.

【美得冒泡】[形] 很美丽, 漂亮极了. 含戏谑或讱讽意. [例] 某甲: “我今天打扮得漂亮吗?” 某乙: “恩, ．”／这女孩自以为 , 同学们都受不了了. 使用地区: 台湾（【beautiful as bubbles】 [adj.] very beautiful, awesomely beautiful. It has the bantering or satirical meaning. [example] A: Do I dress up beautiful today? B: Yes, very beautiful. I The classmates can't stand the girl who believe herself awesomely beautiful. Use of area: Taiwan)

The second example is a good one, which provides a context for the satirical meaning of the word. But the first one provides very vague context to some extent. From the dialogue, we can't tell the tone of speaker B, which is praise or satire. This example is useless for the users to know more information about the headword.

The illustrative examples in this dictionary are written in local Huayu, so there are many featured words in them besides headwords. But the dictionary should respectively offer the reverse way of looking up for those featured words in the examples, otherwise, the examples will confuse the users. For example, “懵查查” means muddleheaded. The dictionary offers sentential examples as follows.

【懵查查】[形] ... [例] 有一次我走错 block 了, 还 地开别人的房间, ... 使用地区: 港澳, 新马泰 (【 muddleheaded】 [adj.] ... [example] Once I went wrong block and open others' room muddleheadedly ... Use of area: Hong Kong, Macao, Singapore, Malaysia, Thailand)

The "block" as an English word will confuse the users who don't know English very well. The illustrative example like this one is less helpful for understanding the headword. Another two examples will explain to what extent should we deal with featured words in the dictionary. “八号风球/八號風球”(No.8 wind ball, in literal) refers to the early warning signals of storm or strong gale sent by Hong Kong Observatory. One of the given example is “天文台发出〜警告信号 , 特区政府提醒市民应立即返家 (The signal has been sent by the Observatory so that the government reminds the public of returning home immediately)”. “返家”(return home) is not a commonly used phrase in Mandarin but it is semantically transparent so there is no difficulty to understand it as returning home. Thus, the example could help users to understand the headword “八号风球/八號風球” without adding more confusions. On the other hands, “市公所” refers to municipal government organization or office areas for municipal government. One of the example of “市公所” is “担任药师的他, 不但和妻子一起到 当志工... (as a pharmacist, he not only serves for city hall as a volunteer...)”. In this sentence, the users in mainland may not be familiar with the word “志工” (volunteer), but if they want to know further, they may look up the dictionary and find it as an article in page 1035. Thus, the dictionary could provide featured words in the illustrative examples, but make sure that the words will not take further problems to the users.

The regional label is an important part for the dictionary, but unfortunately, the dictionary provides incomplete regional labels sometimes. For example, “传译/傳譯” (interpretation) in DGH is labeled as “using in Hong Kong and Macao”. But in fact, it is a common word in Mandarin meaning "interpretation", and included by DCC as well. And 
“simultaneous interpretation” in Mandarin is “同传”, short for “同声传译”. As a synchronic and descriptive dictionary, DGH should label the present usage as precise as it could. Besides, we will discuss two examples about dealing with dialect. The first one is “冲凉” (take a shower) which usually used in Canton (a province in mainland). But the dictionary only labeled it as "using in Hong Kong, Macao, Singapore, Malaysia and Thailand". The exclusion of labeling as “using in mainland" is probably because “冲凉” is a Cantonese dialect rather than standard Mandarin. But the example of “趁钱”(rich) becomes the counter-example. In DGH, “趁钱” is labeled as “using in mainland”, but in DCC, it is labeled as a dialect. Therefore, DGH should make some rules or standards for labeling.

\section{Conclusion}

As the first Huayu dictionary, DGH is a significant and meaningful work. Not only it has showed the global picture of Huayu all over the world and promoted the communication among Chinese all around, but also it could benefit our most important Chinese dictionary, DCC, making some additions or corrections for what have been neglected or missed in DCC. For example, 年假(nianjia, year holiday) in DGH has two senses as follows.【年假】(1)过年期间放的假. [例 ]... (2)指职工每年的带薪假期[例] ...使用地区: (1)大陆, 台湾 (2)大陆, 港澳, 新马泰 (【nianjia】 (1)the vacations for Spring Festival. [example]... (2) the paid holidays in each year for employees. [example]... Use of areas: (1)mainland, Taiwan (2)mainland, Hong Kong, Macao, Singapore, Malaysia, Thailand). From above, the two senses are all used in mainland, that is, in Mandarin. But in DCC, “年假” has been included with two senses: winter holiday and the vacations for Spring Festival. In fact, the description of “年假” in DGH is more precise than in DCC, from the perspective of contemporary Mandarin. In this sense, the revision of DCC could learn experience from DGH.

\section{References}

Chao, J., and Han, J. (eds.). (2005). A Dictionary of Contemporary Chinese (5th edition). Beijing: The Commercial Press.

Guo, X. (2004). Study on Huayu. TCSOL Studies, 2.

Guo, X. (2006). On the Research of Huayu. Applied Linguistics, 2.

Huang, M. (2003). Studies on Malaysia Baba Literature. Master's thesis of ethnology, National City University (Taipei).

Jiang, L. Jingchun, T., and Rong, Ch. (eds.). (2012). A Dictionary of Contemporary Chinese (6th edition). Beijing: The Commercial Press.

Li, Y. (ed.). (2010). A Dictionary of Global Huayu (Chinese Language). Beijing: The Commercial Press.

Yu, G. (2010). Compilation Idea and Practice of A Dictionary of Global Huayu. Issues of the sixth China Youth Symposium.

Zhou Qinghai. The Introduction to the Variation of Huayu in Singapore. http://www.huayuqiao.org/ articles/zhouqinghai.

http://news.sinchew.com.my/node/368990

http://www.cncorpus.org/index.aspx

\section{Note}

${ }^{1}$ Li Yuming (ed.) A Dictionary of Global Huayu (Chinese Language). Beijing: The Commercial Press. 2010. 1148 pages. ISBN 978-7-100-06907-6. Price: 138 RMB. 